\title{
Cytogenetically distinguishable sympatric and allopatric populations of the mosquito Anopheles albitarsis
}

\author{
R. D. Kreutzer (") \\ J. B. Kitzmiller ("*) \\ M. G. Rabbani ("t*)
}

\begin{abstract}
Salivary gland chromosome slides of Anopheles albitarsis from Brasil, Colombia and Venezuela indicate that at least three chromosomally differentiated populations of this species exist in this area. The $B_{1}$ populaijon from Brasil contains one heterozygous inversion in the $\mathrm{X}$ and two in the autosomes. Population $\mathbf{B}_{2}$, sympatric with $\mathrm{B}_{1}$ in Brasil, differs from it by two inversions in the $X$ and ten in the autosomes. Population $\mathrm{C}$ in Colombia and Venezuela is closer to $\mathbf{B}_{1}$, from which it differs by three inversions in chromosome 2 and three in chromosome 3 . Each population, $\mathbf{B}_{1}, \mathbf{B}_{2}$ and C may be distinguished with about $98 \%$ certainty using the banding patterns of the $\mathrm{X}$ chromosomes. Most of the remaining individuals may be identified using a combination of the $\mathrm{X}$ and autosomal paracentric inversions. The scarcity of shared inversions argues for little if any natural hybridization among these populations. A standard salivary gland chromosome map, based on the $\mathbf{B}_{1}$ populations, is presented.
\end{abstract}

\section{INTRODUCTION}

Since the initial studies by Frizzi (1947, 1949) on the European sibling species of the Anopheles maculipennis Meigen complex, considerable information has accumulated on anopheline genetics and cytogenetics. Coluzzi and Sabatini $(1967,1968,1969)$ demonstrated the cytogenetic differences among species in the An. gambiae Giles complex and Davidson et al. (1967) reviewed the crossing studies in this complex. Kitzmiller et al. (1967) have summarized the work on the nearctic $A n$. maculipennis group as well as the relationships between the palearctic and nearctic groups The studies on the European and African anophelines have show that most species with extensive distributions contain population isolates with distinct physiological, ecological chromosomal and even slight morphological differences. Crosses among these populations usually show reproductive isolation; the populations are therefore considered sibling species. Similar relationships exist within the neotropical subgenus Nyssorhynchus Blanchard. Two populations of Anopheles nuneztovari Gabaldon with distinct cytogenetic differences, one associated with malaria transmission and the other not, have been reported (Kitzmiller, et al., 1973). Crossing studies between these two populations have as yet produced only limited data. Two populations of An. darlingi Root appear to be separable only cytogenetically (Kreutzer, et al., 1972). Cytogenetic comparisons between An. darlingi and $A n$. argyritarsis Robineau-Desvoidy show many similarities (Kreutzer, et al., 1975).

Extensive data are available for anothe: species, An. albitarsis Lynch Arribalzaga. This species is widely distributed from Guatemala to Argentina, and along with An. darlingi, An. argyritarsis and An. braziliensis (Chagas) belongs to the argyritarsis series of the subgenus Nyssorhynchus In 1944 Galvão and Damasceno described a subspecies, $A n$. albitarsis domesticus, from eastern Brazil. An a. domesticus appears to be anthropophilic and endophilic, is associated with malaria and filariasis transmission and is larger than $A n$. albitarsis. The latter form, sympatric with Ar? a. domesticus, does not appear to be anthropophilic or endophilic. The species is widely distributed in South America and has been collected in large numbers in both the wet and dry seasons in most areas which have been sampled. This paper describes three popu-

( ${ }^{*}$ ) - Department of Biological Science. Youngstown State University, Ohio, USA.

(*) - Florida Medical Entomology Laboratory. Vero Beach, Florida, USA.

(**) - Instituto Nacional de Pesquisas da Amazônia, Manaus, Brasil. 
lations of An. albitarsis, morphologically alike but chromosomally different. Detailed analysis of the inversions polymorphisms found in these populations will be reported elsewhere.

\section{MATERIALS AND METHODS}

Specimens were collected at localities near Rio de Janeiro in the state of Rio de Janeiro; near Brasilia, Distrito Federal; Porto Nacional, Goiás; Marabá and Capanema, Pará: Macapá, Amapá; and Manaus, Amazonas; all in Brazil. Collections were also made near Villavicencio, Meta, Colombia and near Ciudad Bolivar and Maripa, Bolivar, Venezuela (Figure 1). Both salivary gland and brain cell slides were made following the method, slightly altered, described by French, et al., (1962). The dry-ice method was used to make slides permanent and Zeiss Einschlussmittel LI5 was used as a mounting medium.

Specimens collected as larvae were ident!fied using the keys in Gorham et al., 1967. Nyssorhynchus larvae (short shoulder hairs. branched frontal hairs, palmate leaflets smooth, hair 6 on abdominal segments 4 and 5 unbranched) were classified as An. albitarsis when the following combination of characters was present: well separated inner clypeals: prothoracic hair 1 with lanceolate branches arising from the same level on the shaft; prothoracic hairs 1,2 and 3 arising from a common base. Ten or more such larvae from each site were set aside for emergence and subsequent verification as adults (hind tarsomeres $3,4,5$ all white; short first costal dark area; hind tarsomere 1 with apical ring; first abdominal sternite with two lines of white scales; abdominal segment two without lateral tufts). A considerable number of larvae (about $5 \%$ ) did not have prothoracic hairs 1,2 and 3 arising from a common sclerotized base. Hair one was separated on one or both sides from the base and such Iarva would, if the key were strictly followed, run down to another species. These aberrant larvae were not used for the data in the present paper; they were scored however, then checked chromosomally or allowed to emerge as adults. In all cases they proved to have An. albitarsis chromosome complements or were typical An. albitarsis adults.

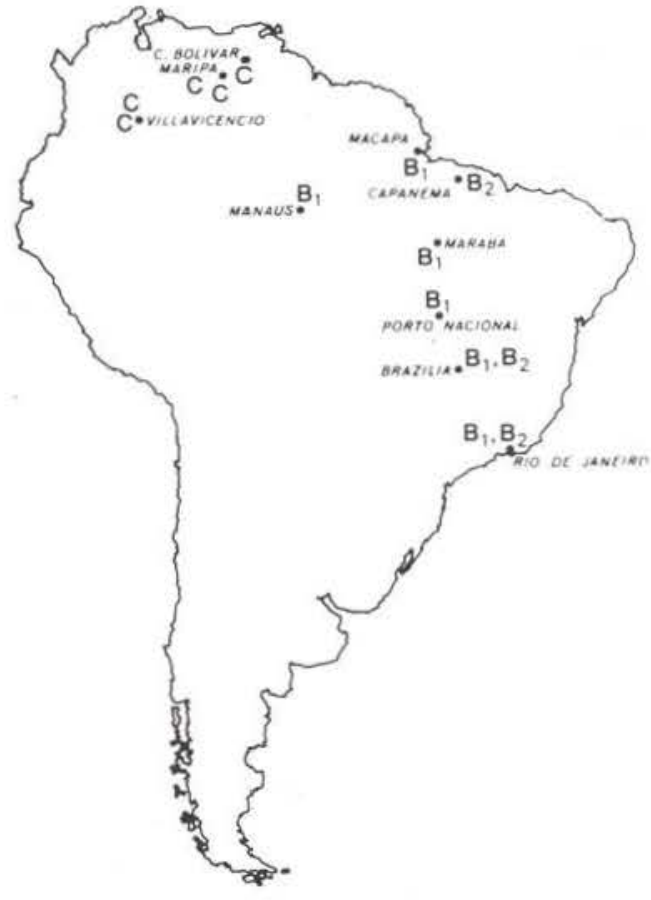

Figure 1, Localities from which $\mathrm{B}_{1}, \mathrm{~B}_{2}$ and $\mathrm{C}$ populations of aibitarsis were collected.

\section{BANDING PATTERNS IN THE (B1) POPULATION}

Three chromosomally distinct populations of An. albitarsis have been identified: $B_{1}$ and $B_{2}$ with a southern and eastern distribution, and $\mathrm{C}$. more northern and western (Figure 1). Figure 2 is the standard salivary gland chromosome complement, and figure 3 is the proposed chromosome map of the standard An. albitarsis sequence. As in all other studied species of the genus Anopheles $2 n=6$, with two pairs of autosomes and one pair of sex chromosomes. The male is heterogametic ( $\mathrm{Fi}$. gure 4). The salivary gland $X$ chromosome is telocentric and averages $60 \mathrm{micra}$; the right arm of submetacentric chromosome two averages 185 micra and the left arm 140 micra. each arm of metacentric chromosome three measures about 140 micra. These arm lengths are about the same as those of An. darlingi and $A n$. argyritarsis and the same numbering system has been used; X-chromosome, zones $1-5 ; 2 R, 6-15 ; 2 L, 16-25 ; 3 R$, zones 26-35; 3L. 36-45 (Kreutzer et al., 1972, 1975). The following descriptions are of the standard set of chromosomes, based on the $B_{1}$ population. 
At the free end of the $X$ chromosome is a distinct series of three dark bands in $1 \mathrm{C}$. The series of dark bands beginning in $3 \mathrm{~A}$ with a close pair and ending in $4 A$ with a series of

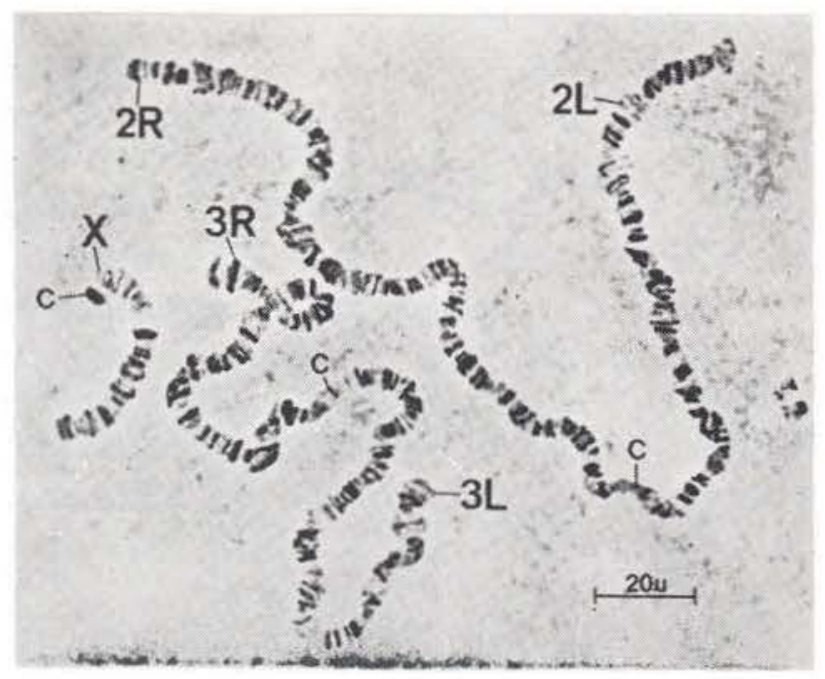

Figure 2. Salivary gland chromosome complement, $B_{1}$ population. four dark bands is characteristic of the center of the arm. The centromere region, $5 \mathrm{C}$, is identical in $B_{1}$ and $C$ and starts with two widely spaced dark bands and ends with the dark band at the centromere (Figure 5) .

In $2 \mathrm{R}$ the two dark bands at the end of $7 \mathrm{~A}$ are good landmarks at the free end of the arm. Two series of dark bands, the first in $9 \mathrm{C}$ and the second in $10 \mathrm{~A}$ are characteristic of the center of the arm and the thick dark bands in $15 \mathrm{~A}$ and $15 \mathrm{~B}$ indicate the centromere region.

In $2 \mathrm{~L}$ the standard arrangement has at the free end a series of five bands in $25 \mathrm{C}$, the first and the third thick and dark and the second, fourth and fifth thin and light; the middle of the arm is characterized by a series of three dark bands at the end of $18 \mathrm{~A}$; the centromere end has three dark bands in 16B (Figure 6).

In $3 R$ the dark wide band at the end of $26 \mathrm{~A}$ is characteristic of the free end of the arm. The series of dark bands starting in $31 \mathrm{~B}$ and ending with the thick dark band at the beginning of $32 \mathrm{~B}$ marks the center of the arm.
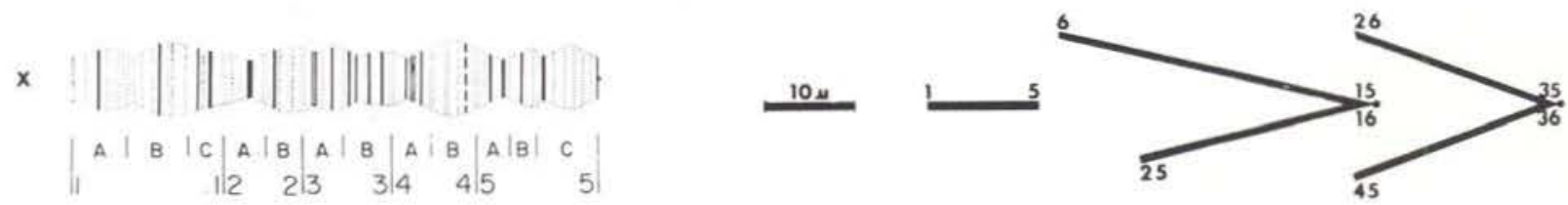

$2 R$

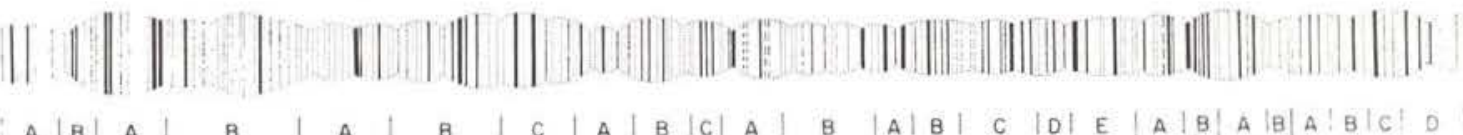

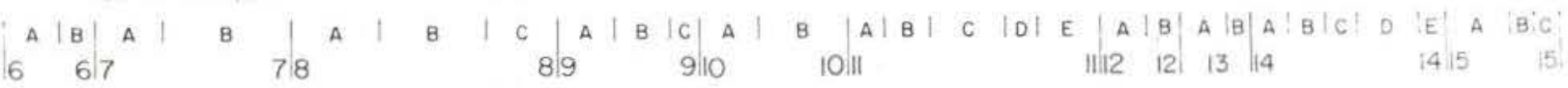

$2 \mathrm{t}$

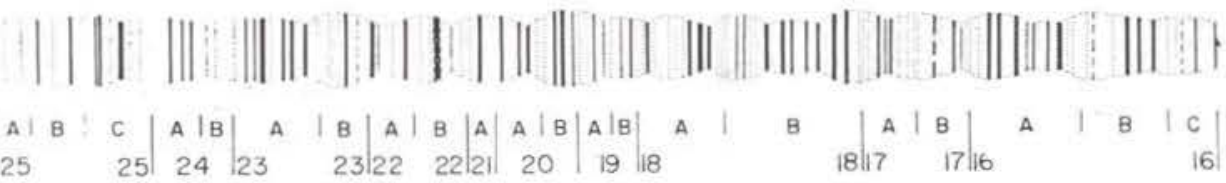

$3 R$

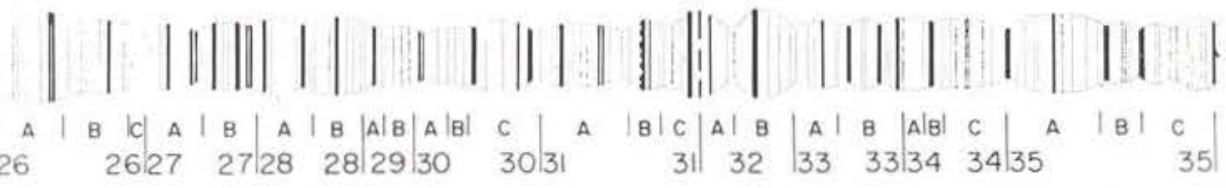

ANOPHELES

ALBITARSIS

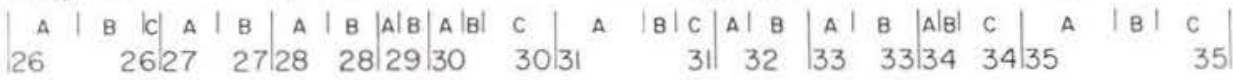

$3 \mathbf{1}$

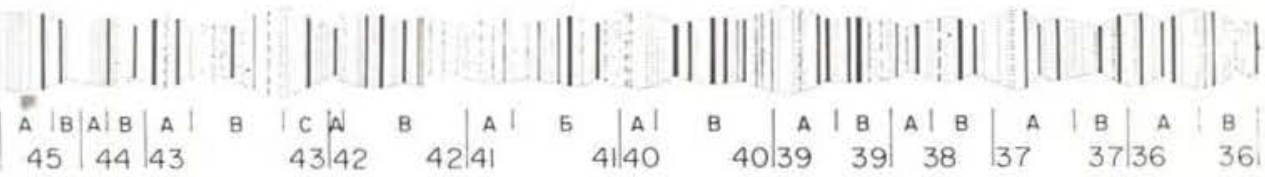

Figure 3. Salivary gland chromosome map, $B_{1}$ 

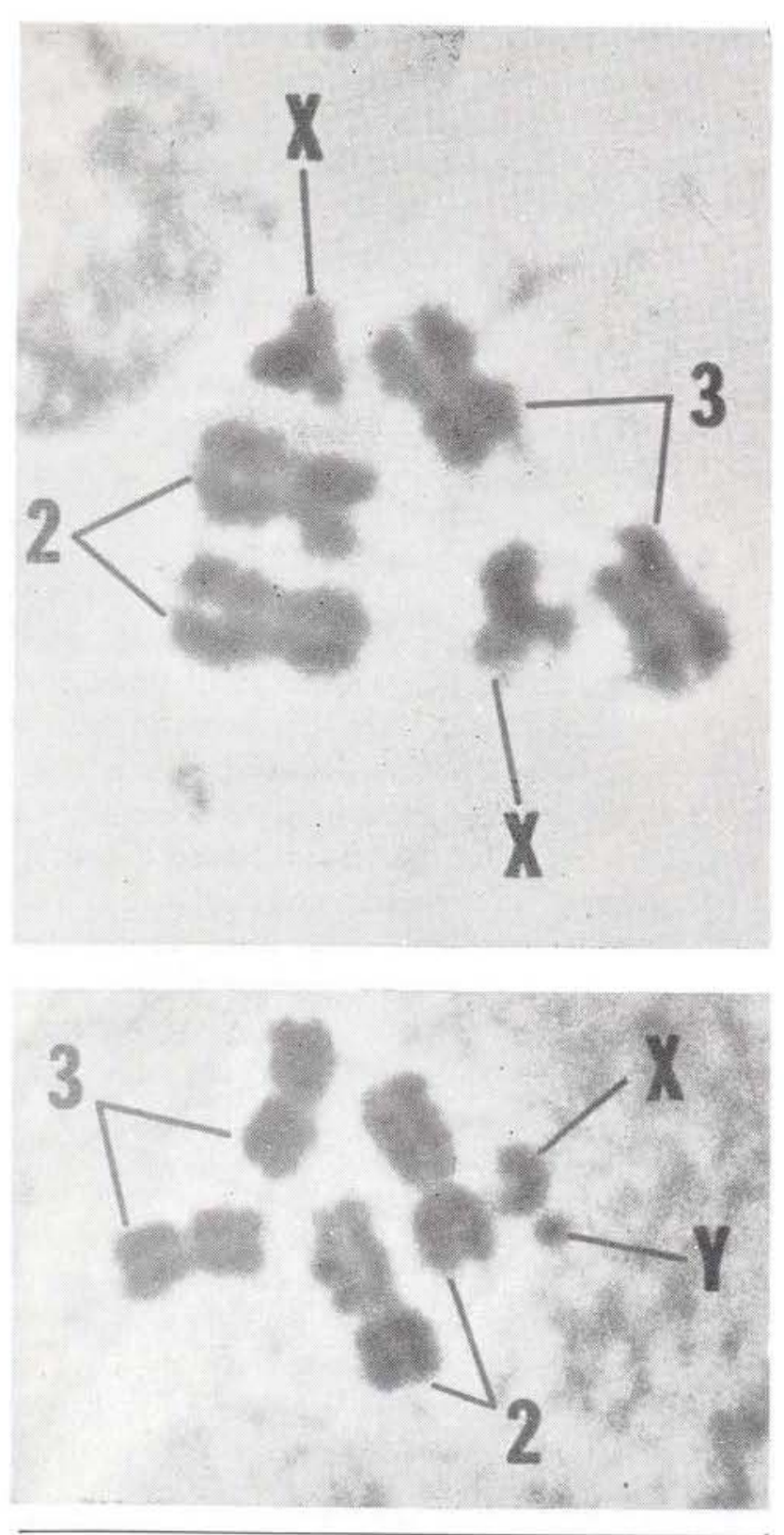

Figure 4. Mitotic chromosomes, $\uparrow$ and $\hat{s}$ pupae.

A series of three dark bands in a puff in $35 \mathrm{E}$ followed by the light bands in $35 \mathrm{C}$ is indicative of the centromere region (Figure 7).

In $3 \mathrm{~L}$ the wide dark band at the end of $45 \mathrm{~A}$, which is followed in $44 \mathrm{~B}$ by a series of lighter bands, is characteristic of the free end of the arm. The two series of dark bands numbered $40 B$ and $39 A-39 B$ in the standard map are easily identified and can be used as a reference area for study of the center of the arm. Several pairs of dark bands mark the centromere region.
The population designated as $B_{1}$ contains three paracentric inversions, one in the $X$, one in $2 R$ and one in $3 R$. These inversions, and other inversions in populations $\mathrm{B}_{2}$ and $\mathrm{C}$ have been named according to a system widely used by Drosophila workers (Wasserman, 1963; Carson, et al., 1967; Coluzzi, et al., 1973). In this system a "standard" arrangement of the salivary chromosome banding pattern is arbitrarily chosen; other populations are then described in terms of inversion differences. For example 2Ra means that the population in question differs from the standard banding pattern by a fixed inversion, "a", based upon a specific region of the standard map. The notation $(\mathrm{a} / \mathrm{+})$ indicates that the population is polymorphic for the inversion which can exist as $+/+$ or a/a homozygotes and a/ + heterozygotes. Each population may thus be described by a formula.

We have arbitrarily designated as the standard arrangement the banding pattern shown in the map (Figure 3 ). This is expressed as the formula $X, 2 R, 2 L, 3 R, 3 L$ (Table 1). The $B_{1}$ population approximates this standard formula in that it differs only in three inversions $\mathrm{X}(\mathrm{a} / \mathrm{+}), 2 \mathrm{R}(\mathrm{f} / \mathrm{+})$ and $3 \mathrm{R}(\mathrm{a} / \mathrm{t})$. All three of these sequences may indeed exist as the $+/+$ arrangement in $B_{1}$ samples; a $B_{1}$ individual with all three $+/+$ sequences would have the same banding pattern as that shown in the standard map.

TABLE 1. Chromosomal formulae for the $\mathbf{B}_{1}, \mathbf{B}_{2}$ and $\mathbf{C}$ populations of Anopheles albitarsis

\begin{tabular}{|c|c|c|c|c|c|}
\hline Standard & $\mathbf{x}$ & $2 \mathbf{R}$ & $2 \mathbf{L}$ & $3 \mathbf{R}$ & 3L \\
\hline $\mathrm{B}_{1}$ & $\mathrm{x}(\mathrm{a} /+)$ & $2 R(f /+)$ & $2 L$ & $3 \mathrm{R}(\mathrm{a} /+)$ & $3 L$ \\
\hline $\mathrm{B}_{2}$ & $\mathrm{Xb}, \mathrm{c}$ & $\begin{array}{c}2 \mathrm{R}(\mathrm{a} / \mathrm{+}) 2 \\
(\mathrm{c} /+) \\
(\mathrm{e} /+) \\
\mathrm{g}\end{array}$ & $\begin{array}{c}(a /+) \\
c\end{array}$ & $\begin{array}{r}3 \mathrm{R}(\mathrm{b} /+) \\
(\mathrm{e} /+)\end{array}$ & $\begin{array}{r}3 \mathrm{La}, \mathrm{b} \\
\text { cde } \\
(\mathrm{a} / \mathrm{b})\end{array}$ \\
\hline C & $\mathrm{Xa}$ & $\begin{array}{c}2 R(b /+) 2 \\
(d /+)\end{array}$ & $(b /+)$ & $\begin{array}{r}3 \mathrm{R}(\mathrm{a} /+) \\
(\mathrm{c} /+) \\
(\mathrm{d} /+)\end{array}$ & $3 \mathrm{~L}(\mathrm{f} /+)$ \\
\hline
\end{tabular}




\section{POPULATION}

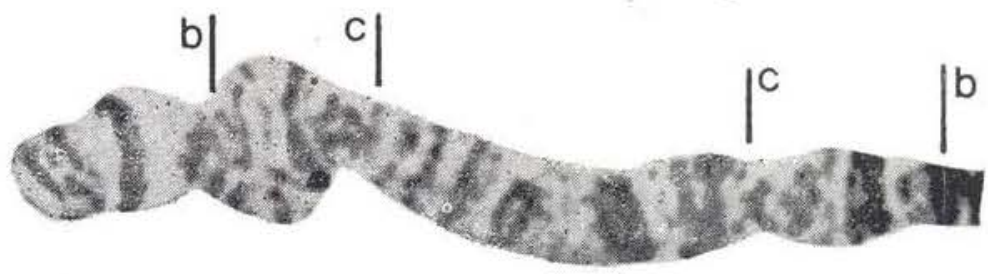

POPULATION

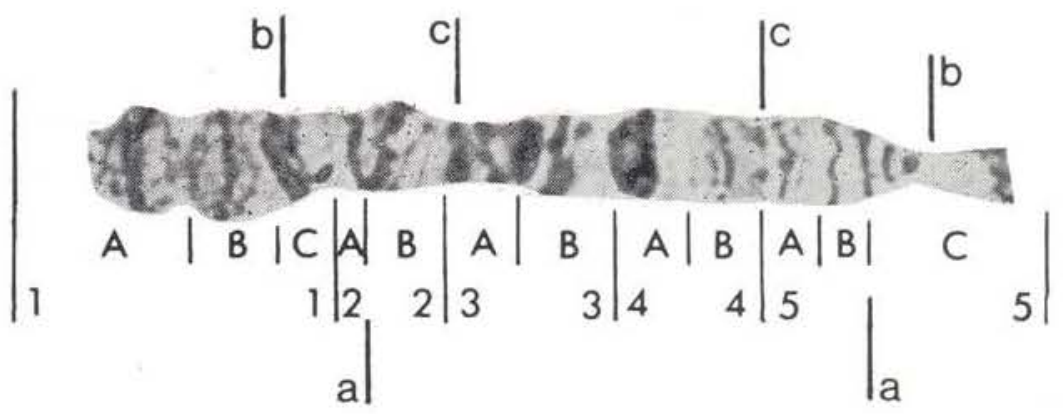

POPULATION

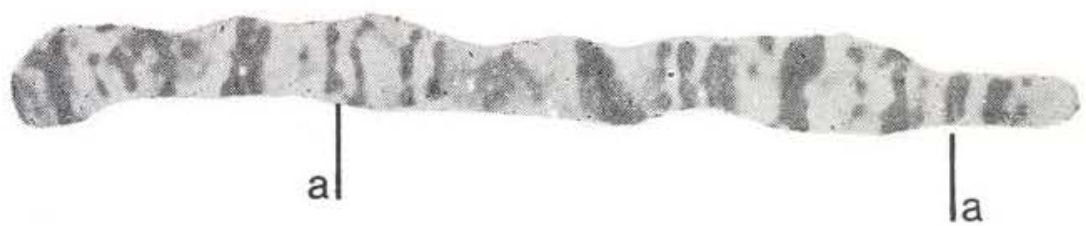

Figure 5. X-chromosomes of the three populations: a, b, c designate inversions. See text and Table 1.

The chromosomal formula for these populations of $B_{1}$ is as follows: $X(a /+), 2 R(f /+)$. $2 \mathrm{~L}, 3 \mathrm{R}(\mathrm{a} /+), 3 \mathrm{~L}$.

\section{BANDING PATTERNS IN THE B2}

AND C POPULATIONS

In the $\mathrm{B}_{2}$ population the apparently distinctive $X$ chromosome is one which appears to have been derived from the standard $X$ sequence by two paracentric inversions. The center of the arm $3 \mathrm{~A}-4 \mathrm{~B}$ is identical in both populations but most of region 5 is now found in region 2 of $B 2$, while $1 C, 2 A$, and $2 B$ of the standard are now in region 5 of $B_{2}$. The details will be reported elsewhere but two separate paracentric inversions are required to produce the $B_{2}$ order. These inversions have evidently become fixed in all the $B_{2}$ populations studied since no heterozygotes were ever found in the $X$ chromosomes (Figure 5).

In $2 R$ the $B_{2}$ samples have four inversions not found in $\mathrm{B}_{1}$. One of these, $2 \mathrm{Rg}$, based on regions $9 \mathrm{~A}-11 \mathrm{C}$ is fixed in all $\mathrm{B} 2$ samples examined thus far. The $12 \mathrm{~A}-14 \mathrm{~A}$ sequence, $2 \mathrm{R}(\mathrm{e} / \mathrm{H})$ is recovered with a high frequency from $B_{2}$ samples. Two other inversions $(a /+)$ and $(\mathrm{c} /+)$ are rare. The $(\mathrm{f} /+)$ inversion characteristic of $B_{1}$ has not been found in $B_{2}$. Except in those individuals with the infrequent $(\mathrm{a} /+)$ and $(\mathrm{c} /+)$ inversions the free and centromere ends of the arm are identical with the standard and the $B_{1}$ sequences (Figure 6 )

In $2 \mathrm{~L}$, a fixed inversion of 25B-23A (2LC) is always associated with the $B_{2}$ type $X$ and is never found in complements with either the $C$ 
$2 \mathbf{R}$
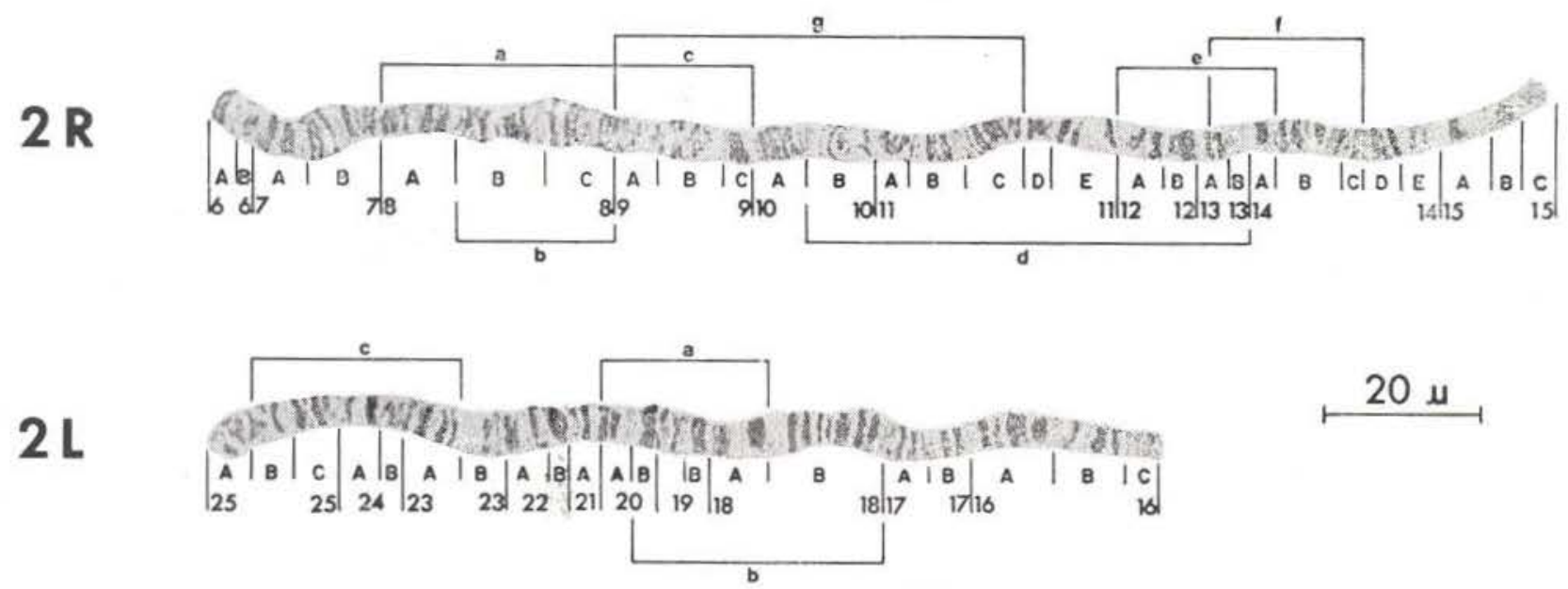

Figure 6. Chromosome two with inversion differences indicated, a, b, c, d, etc. indicate inversions. See text and Table 1. Inversions indicated above the chromosome are found in $\mathrm{B}_{2}$, those below the chromosome are in $\mathrm{C}$, with the exception of $2 \mathrm{Rf}$ which is found in B, only.

or standard $X$ (Figure 6 ). Except for the rare $(a /+)$ inversion, the remainder of the arm does not differ from standard.

In $3 \mathrm{R}$ two common and one rare inversion differentiate $B_{2}$ and $B_{1}$. The 27B-31B (3Ra) inversion is found commonly in $B_{1}$ and the $33 \mathrm{~A}-34 \mathrm{C}(3 \mathrm{Rb})$ inversion is common in $\mathrm{B}_{2}$. Another inversion, $3 \mathrm{Re}$, is similar but not identical to $3 \mathrm{Ra}$, with breakpoints at 27B-31A Onlg one heterozygote for this inversion has been recovered, in the Capanema sample. It thus appears that the inverted sequence, e/e occurs with a very high frequency in $\mathrm{B}_{2}$ popu. lations (Figure 7).

Complex rearrangements are present in $3 \mathrm{~L}$. Two sequences in the center of $3 \mathrm{~L}, 43 \mathrm{~A}$

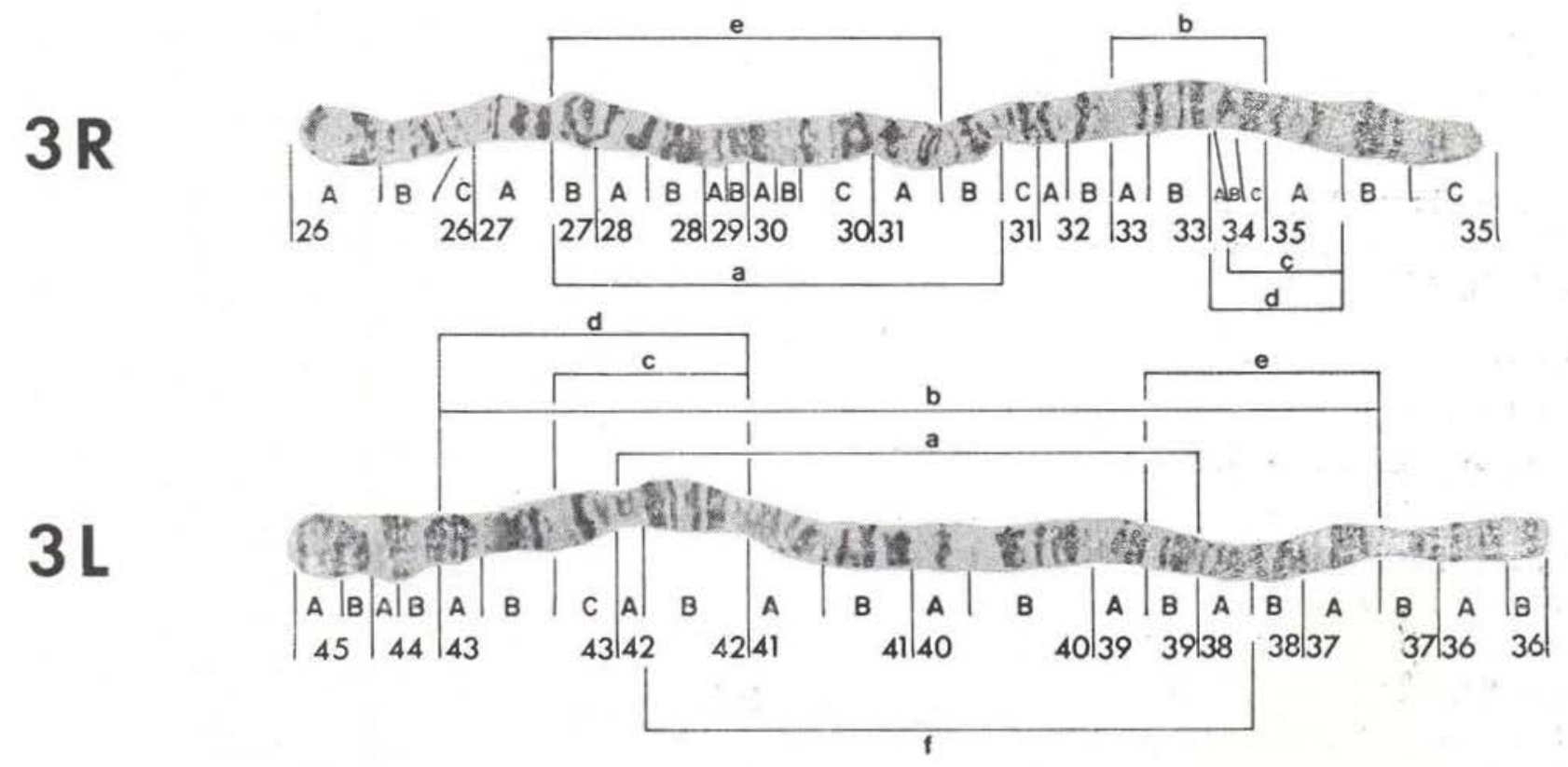

Figure 7. Chromosome three with inversion differences indicated, a, b, c, d, etc. indicate inversions. See text and Table 1. Inversions indicated above the chromosome are found in $\mathbf{B}_{2}$, those below the chromosome are found in $\mathrm{C}$, with the exception of $3 \mathrm{Ra}$ which is found in both $\mathrm{B}_{1}$ and $\mathrm{C}$. 

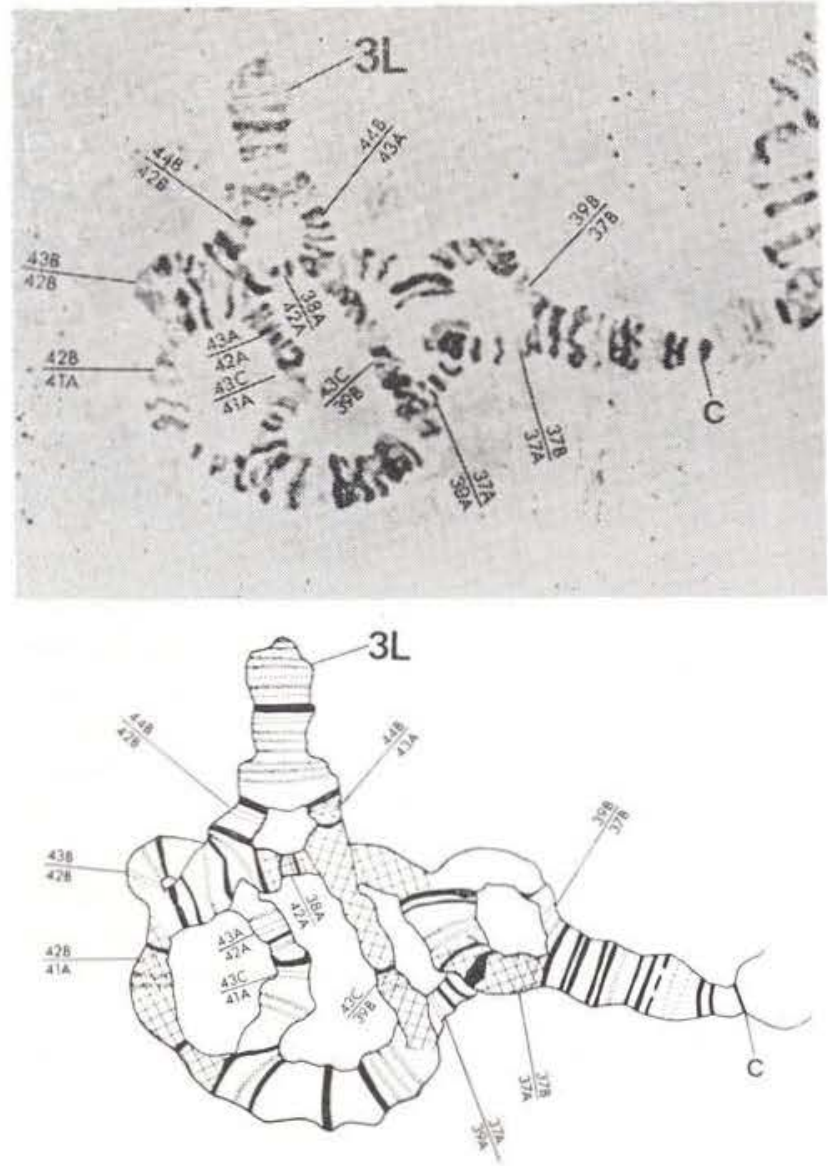

Figure 8. Above - Complex inversion from population $\mathbf{B}_{2}$. Below - Schematic representation of complex inversion.

$37 \mathrm{~A}$, have been recovered. One is a "simple" paracentric inversion involving 42A-39B (3La). This has possibly become fixed in the $B_{2}$ population; it has not as yet been found in the standard or $\mathrm{C}$ populations.

A second paracentric inversion called "complex" extends from 43A to 37A (3Lb). This may be derived from standard by a minimum of three inversions. Details will be reported elsewhere.

The $3 \mathrm{~L}$ standard arrangement has not been found', as yet, in $B_{2}$ populations, nor have the three individual inversions hypothesized to produce the "complex" arrangement. Thus $\mathrm{B}_{2}$ individuals with respect to $3 \mathrm{~L}$ are $3 \mathrm{La} / 3 \mathrm{La}$, $3 \mathrm{La} / 3 \mathrm{Lb}$ or $3 \mathrm{Lb} / 3 \mathrm{Lb}$. The complex pattern resulting from $3 \mathrm{La} / 3 \mathrm{Lb}$ heterozygotes is shown in Figure 8.
The $X$ of population $C$ differs from the standard $X$ in one paracentric inversion (Figure 5) based on 2B-5B ( $\mathrm{Xa}$ ), the same inversion found in $B_{1}$. This inversion appears fixed in population $C$. In $B_{1}$ the $+/+$ arrangemen: is most common but heterozygotes or a/a homozygotes occur with a low frequency (Figure 5 ).

In $2 R$, the $2 R(f /+)$ inversion found in $B_{1}$ ii.s not yet been found in C. Conversely, C contains two inversions $2 \mathrm{R}(\mathrm{b} /+)$ and $2 \mathrm{R}$ $(d /+)$, the former rare, the latter common, not found in either $B_{1}$ or $B_{2}$. $2 L$ in population $C$ is homosequential with standard and $B_{1}$ except for inversion $2 \mathrm{~L}(\mathrm{~b} /+)$ which has been found as heterozygotes only in the Colombian and Venezuelan populations. In $3 R$ the $27 \mathrm{~B}-31 \mathrm{~B}$ inversion, $3 R(a /+)$, is shared by populations $B_{1}$ and $C$. The homozygous inverted sequence (a/a) occurs with a frequency of about $95 \%$ in C complements but with low or moderate frequencies in $B_{1}$ samples. Two short inversions $3 \mathrm{R}(\mathrm{c} /+)$ and $3 \mathrm{R}(\mathrm{d} /+)$ occur with low frequencies, the latter only in the Colom. bian sample.

In $3 \mathrm{~L}$ the $\mathrm{C}$ populations differ from standard by an inversion of 42B-38A $[3 L(f / f)]$. About $65 \%$ of the Venezuelan slides are homozygous $\mathrm{f} / \mathrm{f}$. Chromosomes with this inverted sequence have not been recovered from the Colombian sample of $C$ nor from populations $B_{1}$ or $B_{2}$.

\section{DISCUSSION}

Table 1 summarizes the major inversional differences among the three populations. Although iarvae and adults of all three populations are indistinguishable using conventional taxonomic methods they are clearly distinct cytologically.

Preliminary screening may be accomplished using the $\mathrm{X}$ chromosome; $\mathrm{X}$ chromosomes showing the standard $(+/+)$ pattern in $2 \mathrm{~B}-5 \mathrm{~B}$ (Xa) can be assigned to population $B_{1}, X$ chromosomes with the inverted sequence in 2B-5B (a/a) belong to population $\mathrm{C}$ and $\mathrm{X}$ chromosomes with the distinctive $b / b \quad c / c$ pattern belong to population B2. Heterozygotes for the $2 \mathrm{~B}-5 \mathrm{~B}$ region also may be classified into population $B_{1}$ since $X_{a}$ appears to be fixed in population $\mathrm{C}$. This leaves only the possible a/a individuals of $B_{1}$ which might be mistaken 
for $C$ individuais. About $1.5 \%$ of $B_{1}$ individuals have a/a arrangements. Usually these can be referred to $B_{1}$ by the presence of the $(f /+$; inversion, not found in $\mathrm{C}$ and by the absence of any of the 6 autosomal inversions present in $\mathrm{C}$ but not in $\mathrm{B}_{1}$. There is always of course a very slight possibility of error; an individual homozygous for a/a but with standard patterns $(+/+)$ for both $2 \mathrm{Rf}$ and $3 \mathrm{R}$ a could be confused with a $\mathrm{C}$ individual also homozygous for a/a and $+/+$ for all 7 autosomal inversions. In such rare cases geographical distribution might be an aid; C populations have so far been found only in Colombia and Venezuela. $B_{1}$ and $B_{2}$ populations are often sympatric. Neither $B_{1}$ and $C$ nor $B_{2}$ and $C$ has as yet been found together.

In individuals with autosomal inversions, verification of the $\mathrm{X}$-chromosome identification may be easily provided. Six paracentric inversions are found in $C$ but not in $B_{1}$, one $B_{1}$ inversion does not occur in $C$. Only une inversion (3Ra) is shared by the two populations.

The $B_{2}$ population is of course distinctive. In addition to the unique $X$ chromosome ten paracentric inversions are found in $B 2$ and not found in either $B_{1}$ or $C$. The $B_{2}$ population also has six inversions which have apparently become fixed with respect to the standard pattern and no longer occur as heterozygotes. The $3 \mathrm{La}, 3 \mathrm{Lb}$ situation is also unique in that two inversions, one of them quite complex have become fixed but either $3 \mathrm{~L}$ arrangement may occur. $3 \mathrm{~L} \mathrm{a} / \mathrm{a}$ and $3 \mathrm{~L} \mathrm{~b} / \mathrm{b}$ homozygotes can only be identified with respect to the standard pattern but $3 \mathrm{~L} a / b$ heterozygotes produce a complicated inversion heterozygote (Figure 8) .

The inversion picture would argue for relatively little gene flow among the populations. Only 2 of 21 inversions are shared, $\mathrm{Xa}$ and $3 \mathrm{Ra}$, both shared between populations $\mathrm{B}_{1}$ and $C$, thus arguing for a closer relationship between these populations and a more distant relationship of either $\mathrm{B}_{1}$ or $\mathrm{C}$ to $\mathrm{B}_{2}$. Populations $B_{1}$ and $B_{2}$ are sympatric over wide areas in South America. The inversion picture does not indicate any hybridization between them.
Anopheles albitarsis is often locally abundant in many areas in which malaria transmission is occurring. Although this species is usually considered to be a secondary vector it might be interesting to see if efficient transmission might be correlated with one or more of the cytotypes.

\section{RESUMO}

Estudos citológicos utilizando cromossomos politênicos das glândulas salivares de Anopheles albitarsis, coletados no Brasil, Colômbia e Venezuela indicam que existem pelo menos 3 popula ções, que são diferentes cromossomicamente. Todas as três podem ser diferenciadas usando somente o cromossomo $\mathrm{X}$. A população $\mathrm{B}_{\text {, }}$ do Brasil tem uma inversão heterozigota no cromossomo $\mathrm{X}$ e duas nos autossomos. A população $\mathrm{B}_{2}$, simpátrica com a $B_{1}$, no Erasil, varia daquela por duas inversões no $\mathrm{X}$ e dez nos autossomos. A terceira população C, a qual se encontra na Colômbia e Venezuela, mostra mais proximidade a $\mathbf{B}_{1}$, da qual ela varia por três inversões no cromossomo 2 e três inversões no cromossomo 3 . Cada população, $\mathrm{B}_{1}$, $\mathrm{B}_{2}$ e $\mathrm{C}$ pode ser identificada com 98 por cento de certeza usando a següência das bandas do cromossomo $\mathrm{X}$. A escassez das inversões comuns indica uma baixa taxa de hibridismo na natureza entre estas populações. É apresentado um mapa dos cromossomos de glândulas salivares de larvas da população $B_{1}$ para ser considerado como padrão para esta espécie.

\section{LITEFATURE CITED}

Carson, H. L.; Clayton, F.E. \& Stalker, H.D.

1967 - Karyotypic stability and speciation in Hawaiian Drosophila. Proc. Nat. Acad. Sci., U.S., $57:$ 1280-1285.

Coluzzi, M. \& Sabatini, A.

1967 - Cytogenetic observations on species A and $B$ of the Anopheles gambiae complex. Parassitologia, 9: 7388 .

1968 - Cytogenetic observations on species C of the Anopheles gambiae complex. Parassitologia, $10: 155-165$.

1969 - Cytogenetic observations on the salt water species, Anopheles merus and Anopheles melas, of the gambiae complex. Parassitologia, $11: 177-187$.

Coluzzi, M.; Di DeCo, M. \& CANCRINI, G.

1973 - Chromosrmal inversion in Anopheles stephensi Parassitologia, 15: 129-136. 
Davidson, G.; Patterson, H. E.; Coluzzi, M.; MASON, G.2. \& MICKs, D.W.

1967 - The Anopheles gambiae complex. In: Wright \& Pal eds. - Genetics of insect vectors of disease. Amsterdam, Elsevier publ., Chspter 6: 211-250.

FRENCH, W.R.; BAKER, R.H. \& KrTZMHLler, J.B.

1962 - Preparation of mosquito chromosomes. Mosq. News. $22: 377-383$.

FrIZZI, G.

1947 - Cromosomi salivari in Anopheles ma culipennis. Sci. Genet. (Toriho) 3:67-79.

1949 - Genetica di popolazioni in Anopheles maculipennis. Studi preliminari sui riordinamenti cromosomici del gruppo. Ricerca Scient., 19 : 544-552.

Galvão, A.L.A. \& Damasceno, R.G.

1944 - Observações sobre anofelinos do complexo albitarsis (Diptera: Culicidae) Ann. Fac. Med. São Paulo, 20 : 73-87.

Gorham, J.R.; Stojanovich, C.J. \& Soott, H.G.

1967 - Illustrated key to the anopheline mosquitoes of eastern South America. Atlanta, U.S. Dept. of HEW USPHS. $64 \mathrm{p}$.
KrTZMiller, J.B.; Frizzi, G. \& BAKER, R.H

1967 - Evolution and speciation within the maculipernis complex of the genus Anopheles. In: Wright \& $\mathrm{Pal}$ eds. Genetics of insect vectors of disease. Amsterdam, Elsevier pub., Chapter 5 : 151-210.

Kitzmiller, J.B.; Kreutzer, R.D. \& TAllaferro, E.

1973 - Chromosomal differences in populations of Anopheles nuneztovari. Bull. Wld. Hith Org.; $48: 435-455$.

Kreutzer, R.D.; KItZMiller, J.B. \& Ferreira, E.

1972 - Inversion polymorphism in the salivary gland chromosomes of Anopheles darlingi Root. Mosq. News, $32: 555-565$.

KREUtZer, R.D.; KITZMiller, J.B. \& RABBANI, M.G. 1975 - The salivary gland chromosomes of Anopheles argyritarsis R.-D. compared with those of certain other species in the subgenus Nyssorhynchus. Mosq. News, $35: 354-365$.

WASSERMAN, M.

1963 - Cytology and phylogeny of Drosophila. Amer. Nat., $97:$ 333-352. 